\title{
El Street Art y la (in)cultura urbana: el ejemplo de Córdoba
}

\section{Street Art: urban culture, urban ignorance. The example of Córdoba}

\author{
Pablo Allepuz-García \\ Universidad de Córdoba \\ pabloallepuz@gmail.com
}

Recibido: 23 de diciembre de 2012

Aprobado: 19 de julio de 2013

\section{Resumen}

El Street Art es un fenómeno artístico presente en nuestra vida diaria al que se ha condenado a un cierto ostracismo. Tanto la comunidad académica, en este aspecto ajena a lo que ocurre en el mundo real, como la gran mayoría de la sociedad, inmersa en preocupaciones bien distintas, han obviado su existencia ineludible no ya en el arte, sino en el propio paisaje urbano; aun cobra un sentido más crudo en la Ciudad Histórica, donde la ingente cantidad de Patrimonio eclipsa cualquier otra manifestación. Este trabajo abre una nueva línea de investigación en Córdoba, partiendo de un análisis de la sociedad en que se origina y de aquello que significa; documentando sus representaciones más significativas sobre una base cartográfica; aplicando la experiencia estética como fundamento de nuestra reflexión; y, con base en lo anterior, realizando algunas propuestas de interpretación. Todo ello, con posibilidades de ser extrapolado a otras ciudades españolas. Palabras clave: Street Art, Córdoba, Graffiti, Cartografía, Experiencia Estética.

Allepuz-García, P. (2013): El Street Art y la (in)cultura urbana: el ejemplo de Córdoba. Arte, Individuo y Sociedad, 26 (1) 137-151

\begin{abstract}
Street Art is an artistic phenomenon that, although present in our everyday lives, has been condemned to a certain ostracism. On the one hand, the Academic Community is -in this field-oblivious to what happens in real world; on the other hand, the vast majority of our society is immersed in very different concerns. Both of them have avoided its inevitable existence not only in art panorama, but also in the urban landscape. The problem takes a harder perspective within the Historical City, where the variety of the Heritage outshines any other manifestation. This study opens a new research line in Córdoba, starting with an analysis of the society from which Street Art is created and what it means, documenting its most significant features on a cartographic map, applying the aesthetic experience as the foundation of our own thinking, and, based on this, making some proposals for interpretation. All of these conclusions have the potential to be applied to other Spanish cities.
\end{abstract}

Key words: Street Art, Córdoba, Graffiti, Cartography, Aesthetic-Experience.

Allepuz-García, P. (2013): Street Art: urban culture, urban ignorance. The example of Córdoba. Arte, Individuo y Sociedad, 26 (1) 137-151

Sumario: 1. Introducción, 1.1. Concepto de Street Art, 1.2. Statu quo, 2. Córdoba: el dibujo del flâneur, 2.1. Cartografía, 2.2. Interpretación de la cartografía, 3. Estética y Filosofía del Arte (Urbano), 3.1. Erótica, 3.2. Hermenéutica, 3.3. Metaposición analítica, 4. Conclusiones: problemas y posibilidades del Street Art. Referencias 


\section{Introducción}

Una sociedad sin arte es una sociedad sin vida (Lima, 2011)

"La sociedad urbana, occidental u occidentalizada de hoy en día se ha fragmentado en una serie de subculturas diferentes, aunque solapadas, cada una con una identidad musical propia" (Cook, 2001: 18). La complejidad de nuestro Zeitgeist radica en la aparente confluencia de estilos, el sincretismo que supone la globalización; sin embargo, no debe considerarse únicamente producto de nuestro tiempo -que algunos coinciden en denominar hipermodernidad, superando el postmoderno de Lipovetsky o Lyotard (Cfr. Thiebaut, 1999)-, sino resultado de la perspectiva sincrónica: ante la imposibilidad de aislar el presente hemos de recurrir al pasado más reciente, que con tanta frecuencia hunde sus raíces en lo más profundo de la Historia.

El siglo XX ha sido especialmente convulso en todos los ámbitos de la vida: es el siglo de las Guerras Mundiales, la bomba atómica y los campos de concentración; del triunfo del capitalismo, el Crack del 29 y la caída del muro de Berlín; del advenimiento de la democracia, la información y los mass media; del fin del arte, las vanguardias y las subastas. Un arte que no podía ya recrearse en elitistas mundos idílicos, sino que debía comprometerse con la realidad, mezclarse con nosotros, ponerse a ras de suelo: adoptando formas insospechadas, ha abandonado incluso sus habituales residencias privadas para abrazar la ciudad en tanto que lugar común de la sociedad. En este contexto, toda reflexión sobre el arte puede canalizarse a través del Street Art una vez "ha llegado a ser evidente que nada referente al arte es evidente: ni en él mismo, ni en su relación con la totalidad, ni siquiera en su derecho a la existencia" (Adorno, 1983: 9). La manera en que lo tratamos dibuja una radiografía de nuestro estado mental, se establece como un espejo en el que mirarnos; aunque la decisión de hacerlo haya quedado - por unas razones u otras- a título personal.

\subsection{Concepto de Street Art}

We declare the world as our canvas!

[Declaramos el mundo como nuestro lienzo] (Street Art Utopia)

Pero, ¿qué es el Street Art? Para muchos se trata de un mero oxímoron, una irreverente muestra de la degeneración moral que nos atañe; otros, a su vez, aprecian en tal aspecto -la transgresión- la verdadera esencia de todo acto artístico contemporáneo, siendo el Arte Urbano, por tanto, su epígono y máximo exponente ( $C f r$. Julius, 2002). Este baile sobre la delgada línea que separa arte y política, algo exclusivo de nuestro definiendum, es un arma de doble filo que, no obstante, podría y debería desembocar en una reflexión sobre la sociedad en sí misma. Pero para desarrollar una exégesis de semejante magnitud hemos de conocer siquiera la naturaleza y el contenido de nuestro objeto. Lato sensu, el Street Art engloba cualquier actividad artística que tenga como contexto el entorno urbano, hallando concreción en ciertas manifestaciones: 
movimientos como Recuperar Las Calles (Cfr. Klein, 2001: 363-376), que llevan a cabo performances en público; flashmobs, smartmobs, happenings; la contracultura del hip-hop con el graffiti, el stencil o el shoeffiti; la música en la calle; intervenciones merecedoras de estudios individuales y exhaustivos que habrán de ser abordados en otro momento.

Ahora bien, ¿qué es el arte? A priori parece una pregunta sencilla, pero no lo es en absoluto (Cfr. Jiménez, 2002); aun se complica más al tratar el Street Art, pues no todo lo relativo a dichas prácticas es considerado arte: dado su carácter rebelde e ilegal puede incluso tacharse de vandalismo -la valoración más extendida-. Otro aspecto a tener en cuenta es su fenomenología efímera, en la que prima el anónimo proceso creativo sobre la obra resultante: ésta puede perdurar indefinidamente o desaparecer al cabo de algunas horas. Ese proceso de producción de obras, tan emparentado con el Capitalismo, se desvanece aquí a favor de la propia expresión artística.

The irony is that despite having to scuttle around at night like Jack the Ripper with a marker pen, writing graffiti is about the most honest way you can be an artist. It takes no money to do it, you don't need an education to understand it, there's no admission fee and bus stops are far more interesting places to have pictures than in museums [La ironía es que a pesar de tener que merodear por la noche como Jack el Destripador con un rotulador permanente, pintar grafitis viene a ser la forma más honesta de ser artista. No exige dinero para hacerlo, no requiere una educación para entenderlo, no hay que pagar entrada y las marquesinas son lugares mucho más interesantes para ubicar las pinturas que los museos] (Banksy, 2001: 5).

Al menos esa es la parte teórica. La popularidad de Banksy, convertido en un icono pop, ha hecho del Street Art materia de la opinión pública internacional gracias a la comercialización de su marca: toda una estrategia de merchandising, disimulada por la ambigüedad de su implicación en los beneficios y su celoso anonimato, en la que encontramos tres libros e, incluso, una película -Exit through the gift shop (2010) - que podría resumir metafóricamente su trayectoria artística, esto es, desde unos orígenes humildes y arraigados hasta la fama mundial; para algunos, como Space Hijackers, desde la pureza ética y política de las formas primeras hasta la actual prostitución de su obra dentro del sistema. Shepard Fairey se encuentra en una situación similar: de su alter ego $O B E Y$ a la campaña electoral de Obama, pasando también por la venta de su logo en numerosos productos. En consecuencia, por estos y otros ejemplos, se ha generado una fuerte controversia en el seno del Street Art: el favoritismo y el privilegio del que gozan estos entre sus iguales provoca un rechazo que se transforma en boicot a sus piezas. La polémica está servida, aunque se trata de un debate que aún -y subrayo el complemento temporal- no se ha generado en España. 


\subsection{Statu quo}

Never paint graffiti in a town where they still point at aeroplanes [Nunca pintes grafitis en una localidad donde aún señalen a los aviones] (Banksy, 2001: 43).

El lenguaje, por sí mismo, nos da claves analíticas del estado de la cuestión: hablamos de Street Art, graffiti, stencil, performance... Tanta cursiva no viene sino a indicar que España sigue una inercia exterior, sin asimilar por completo el contenido de dicho movimiento. En efecto, no es sencillo estudiar este fenómeno, debido a su -digámoslo así- modernidad, heterogeneidad y dispersión. La bibliografía no es abundante y su difusión dista mucho de ser ejemplar, con títulos difíciles de encontrar, la mayoría de fuentes digitales y en otros idiomas; en muchas ocasiones, la solución es recurrir a los pocos entendidos en la materia, que suelen prestar su ayuda en pro de un mayor conocimiento de su cultura. Existe, además, una tendencia generalizada a ponderar en exceso lo visual, a analizar la voluntad del artista en lugar de extraer los valores directamente de la obra de arte para trascenderla. Se han producido avances, pero aún se ha escrito muy poco sobre el tema en nuestro país: podemos destacar algunas tesis doctorales (Figueroa Saavedra, 1999; Abarca Sanchís, 2010), libros (De Diego, 2000; AA.VV, 2005) o artículos específicos (López Jiménez, 1998; Cambil Hernández, 2012); al margen, por supuesto, de otro tipo de acercamiento como programas de televisión (Ritmo Urbano, 2012-2013) o documentales (Las Calles Hablan, 2013).

En el caso concreto de Córdoba, podríamos reducirlo hasta una absoluta ignorancia: apenas se limita a esporádicas apariciones en prensa. Pese a no contar con una base de investigación sólida, el Street Art está presente en la urbe: por tanto, merece ser rescatado del olvido para propiciar la reflexión que tanto tiempo se le ha negado; obviar su existencia supone mantener un tabú envuelto en prejuicios.

Córdoba es una ciudad un tanto pasiva respecto a su cultura. La institucionalización de los principales monumentos, así como el papel de los museos, generan en la población un cierto sentimiento de despreocupación por su Patrimonio: si ya existe un entramado que explota los bienes culturales, la contribución particular no es necesaria. Craso error: la ciudad está perdiendo su espontaneidad, su capacidad de conquistar las calles con actividades de cualquier tipo -más allá del flamenco, los patios, las cruces o las terrazas-. A pesar de las puntuales acciones de la reciente plataforma Emplazarte, aún con escasa visibilidad, del intrigante caso del Callejero pirata, desvelado el misterio en las personas de Antonio Blázquez y Cristian Tena (Diario Córdoba, 14/10/12), y de algunos talleres (Diario Córdoba, 26/07/12) y cursos (El Arsenal de Chinales) de reducido público, la noción de performance es una perfecta desconocida; la música en la calle, por desgracia, una bella anécdota; prácticamente lo único que mantiene viva la llama del Street Art es el graffiti, y su variante en stencil. Como trasunto, el trabajo debe inclinarse en lo sucesivo hacia esta vertiente, por su omnipresencia en el paisaje urbano y la insuficiente atención que ha recibido: "Graffiti ultimately wins out over proper art because it becomes part of your city" [El graffiti se impone sobre el arte institucional porque pasa a formar parte de la ciudad] (Banksy, 2001: 5). 
Hacemos en este momento un inciso para aclarar la terminología: preferimos el término internacionalmente aceptado graffiti, así como el plural castellanizado "grafitis" para suplir su ambigüedad; sin olvidar, por ello, su más antigua raíz italiana graffito, de la que derivan las demás.

\section{Córdoba: el dibujo del flâneur}

Escúchela; la ciudad respirando... (Black Star, 1998) .

Muchas son las obras repartidas por la geografía cordobesa, aunque pocas han tenido la repercusión del citado Callejero pirata. En verano del 2010, las fachadas de numerosos edificios, la mayoría en estado de abandono, amanecieron cubiertas por letras de papel pintado que proponían nuevos nombres para el intrincado urbanismo de la ciudad. A imitación del representativo estilo de los rótulos institucionales y oficiales, leyendas como "por fin te he encontrado", "el quinto pino", "he encontrado un atajo" o "to' pa' lante" duplicaron el significado de los caminos, robando, de paso, una sonrisa cómplice a los viandantes. El Ayuntamiento, por clamor popular, decidió mantenerlos en las paredes. Otro caso es el de $L o$, quien imprime su particular lectura del Street Art mediante stencils que reproducen libros, depositados amorosamente sobre los dinteles o en el acto de emprender un vuelo hacia no se sabe dónde. Llenan así de cultura, literalmente, todos los rincones. Black-T, por su parte, ha desarrollado un estilo personal e inconfundible, caracterizado por unas figuras humanas que contraponen la esquematización de las formas del cuerpo al realismo y la inocencia de los rostros en escala de grises.
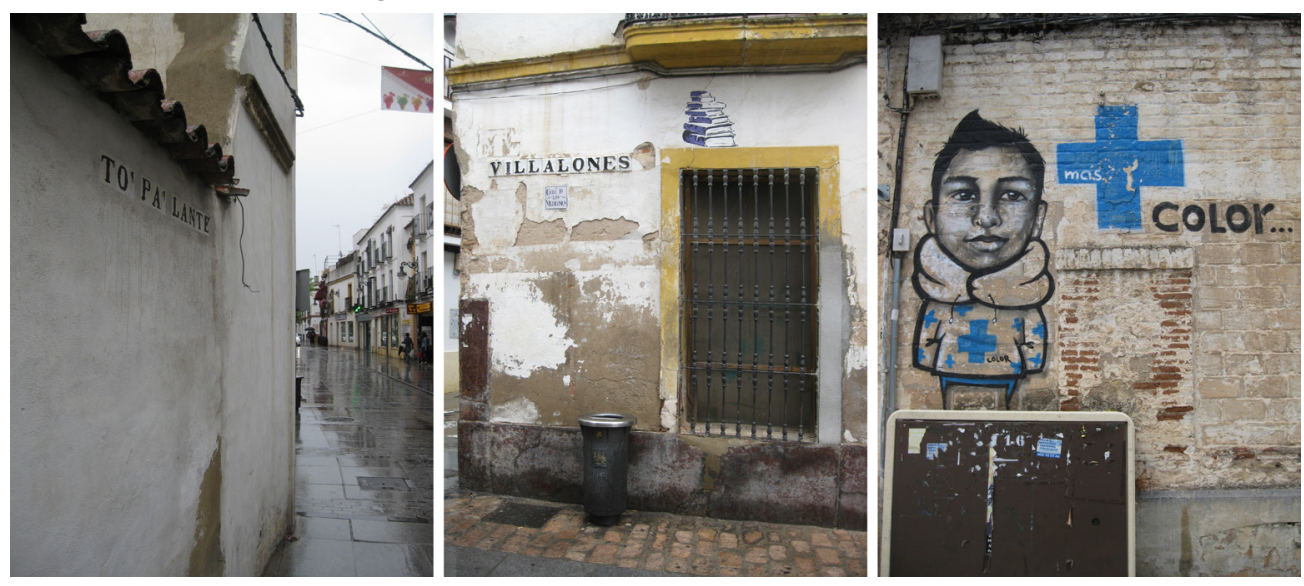

Figura 1. Rótulo de Callejero Pirata, libros de Lo junto a un rótulo institucional y niño de Black-T, respectivamente. (Fotografías de elaboración propia)

En esta apología de la ciudad, escenario del gran teatro del mundo, "l'art de vivre dans la ville comme oeuvre d'art" [el arte de vivir la ciudad como obra de arte] (Lefebvre, 1974: 139) se encarna en la figura del flâneur: a cada forma de mover- 
se corresponde una forma específica de conocer, y la del flâneur es un divagar que memoriza. No le interesa el adónde, sino el dónde (Cfr. Schlögel, 2007: 257-262). Nuestros caminos se cruzan en este punto, ya que hemos de recorrer las calles para documentar los elementos de nuestro estudio; $y$, con ellos, configurar el paisaje urbano del Street Art sobre un plano de Córdoba.

Es evidente que no podríamos seleccionar todo lo que haya salido de un bote de spray por el simple hecho de haber empleado dicho procedimiento: identificar técnica y obra perjudica a la consideración artística del graffiti. Si bien cualquier elemento puede ser interpretado como arte -refugio de la mediocridad en demasiadas ocasiones-, hemos de establecer un criterio a la hora de incorporar a nuestro trabajo tal o cual ejemplar; criterio, por cierto, que puede no ser compartido -dentro de aquel relativismo coexisten tantos como personas y formas de entender el arte-. Así pues, se incorporarán al mapa aquellas piezas cuya intencionalidad o valores estéticos destaquen sobre el común de "pintadas": es decir, se discriminarán mediante omisión las restantes, que a los ojos de la sociedad no demuestran ninguna aportación y, por el contrario, sólo parecen contaminar visualmente el entorno. Adoptar esta posición implica imprimir al conjunto una acusada pátina de subjetividad que, no obstante, trataremos de paliar constituyendo un amplio cuerpo calificable como arte -para la subjetividad, véase el apartado 3.1-. El objetivo se aleja así de la documentación sistemática, que quedará apuntada para un estudio posterior, y se utilizarán obras concretas como herramienta didáctica: el ostracismo del que se habla en el resumen es un problema de educación, y resulta ciertamente más sencillo comenzar una explicación por los ejemplos paradigmáticos para poder comprender, al fin, el Street Art en toda su expresión.

Callejear es una especie de lectura de las calles, donde caras, escaparates y vitrinas, terrazas, vías, coches, árboles, [grafitis,] todo se convierte con igual derecho en letras que juntas producen palabras, frases y párrafos de un libro siempre nuevo. Para callejear como es debido no vale tener en la cabeza nada demasiado definido (Hessel, 1984: 145).

La ciudad está repleta de pequeños destellos que cada día se reproducen y desaparecen. Haga el ejercicio de buscarlos y lo descubrirá por usted mismo: en palabras del citado Henri Lefebvre, el futuro del arte no es artístico sino urbano (1974: 140).

\subsection{Cartografía}

Mind the map! [iCuidado con el mapa!] (London Transport Museum, 2012)

Una de las ironías de nuestra época es que ahora, cuando las calles se han convertido en el artículo más valioso de la cultura publicitaria, las manifestaciones de cultura se hallen bajo amenaza. Los ataques contra los grafitis, los pósters o la mendicidad están criminalizando todo lo que hay de realmente público en la vida de las ciudades (Klein, 2001: 363-364). Si, como decimos, el carácter del Street Art es meramente efímero, puesto que puede desaparecer en cualquier momento, ¿qué sentido tiene presentar una visión sincrónica del mismo? A lo largo de los siglos, el arte ha tratado 
de desentenderse del espacio para trascender su tiempo; el Street Art, en cambio, establece un espacio sin ambicionar la eternidad. Bien es cierto que los grafitis nacen con fecha de caducidad y, a pesar de ello, los emplazamientos donde tienen lugar -y el espíritu de este apartado es el espacio- suelen perpetuarse. De este modo, las obras de arte se superponen, se alteran, se deterioran y mueren, pero el espacio creativo, el paisaje artístico permanece vivo; y en tanto que vivo, cambiante.

Este apartado, ampliamente subdividido según los barrios en que se organiza Córdoba, trata de recoger la cartografía temática del graffiti en la ciudad. Es, por tanto, una tarea ambiciosa e imprudente a partes iguales, dadas la ingente cantidad de manifestaciones por documentar, la amplia extensión en que se encuentran repartidas y su constante peligro de extinción.

La textura de una ciudad refleja una suma de lugares complementarios que se yuxtaponen, superponen o encadenan. Cada lugar tiene su característica propia, sin pretensión alguna de inmutabilidad. De ahí que pueda leerse la ciudad como collage en que las formas de construcción ponen de manifiesto posturas urbanísticas, crítica social y modos de trato con la Historia (Schlögel, 2007: 303).

Los barrios constituyen las distintas piezas de un puzle que terminará ensamblándose una vez que todas sus partes estén detalladas componiendo, pues, un completo esquema del panorama urbano de Córdoba. Sin embargo, la enorme complejidad de una ciudad, con infinitud de factores históricos, económicos y sociales distribuidos de manera desigual, no permite abordar su estudio completo en un simple artículo; ni siquiera el de un barrio individual. Por tanto, adaptándonos al formato, incluimos solamente algunos de los ejemplos más relevantes de Ciudad Jardín como apoyo al texto y como una imprecisa aproximación al estudio exhaustivo que se podrá llevar a cabo en el futuro: pretendemos advertir del sentido peyorativo y discriminatorio que estas representaciones adquieren en el imaginario colectivo, que incluso se ha convencido de su inexistencia. La elección de dicho entorno responde asimismo a motivos arbitrarios y asumimos la relatividad de las impresiones que se pudieran extraer: el mapa no refleja todo el Arte Urbano de Córdoba ni tampoco de la zona abarcada, sino aquello que más fácilmente puede ser identificado y aceptado por el ciudadano, al tiempo que describe unas ligeras pinceladas sobre la metodología a aplicar en el caso del estudio exhaustivo que se realizará a posteriori. 


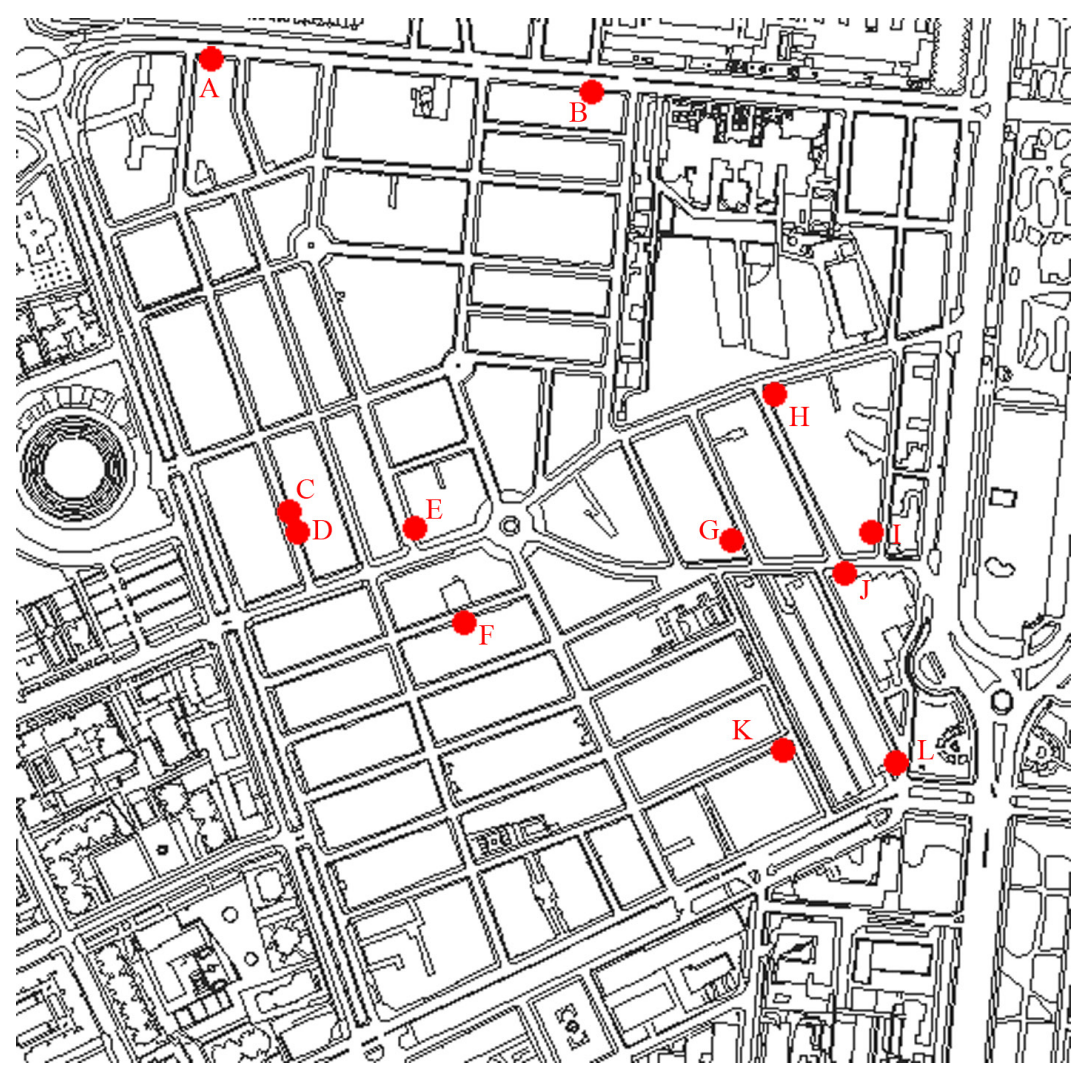

Figura 2. Mapa temático del barrio Ciudad Jardin, en el que se disponen algunas de las piezas más representativas. (Elaboración propia sobre el plano de Córdoba cedido por la Gerencia Municipal de

\subsection{Interpretación de la cartografía}

These walls don't lie... [Esos muros no mienten] (Promoe, 2004)

Cuando el mapa completo de Córdoba - macroestructura- esté confeccionado, podrá reflexionarse sobre aspectos como la diferencia de estilos entre barrios, la distinta profusión según zonas, el grado de actividad de cada una de ellas... Entretanto, no podemos adelantar más que unas palabras sobre el barrio elegido -microestructura-: Ciudad Jardín está infestada e infectada de grafitis de todas las tipologías, si bien la proporción entre el artístico y el vandálico es vergonzosamente preocupante; la mayoría de aquellos, por cierto, sirven como imagen a privados. No existe, en ninguno de ellos, una coincidencia estilística que apunte a un grupo o un artista determinado, como tampoco aparecen firmas que reivindiquen dichos trabajos; más bien, debemos hablar de manifestaciones individuales y anónimas, sin conciencia de autoría ni voluntad de prestigio. A pesar de la aleatoriedad de su disposición, podemos distinguir 
algunas zonas de mayor concentración, en un ejercicio de mimetismo bastante común. Como decimos, todo ello se contrastará más adelante con las partes restantes para obtener los resultados. Nuestro interés en este artículo no es la documentación exhaustiva de la zona ni la atribución a uno u otro artífice, que aún deben esperar un tiempo prudencial, sino demostrar que existen suficientes manifestaciones para iniciar una discusión sobre su consideración. Así pues, prescindimos de un catálogo descriptivo de todas ellas e integramos algunos ejemplos con el único propósito de ilustrar los argumentos del discurso.

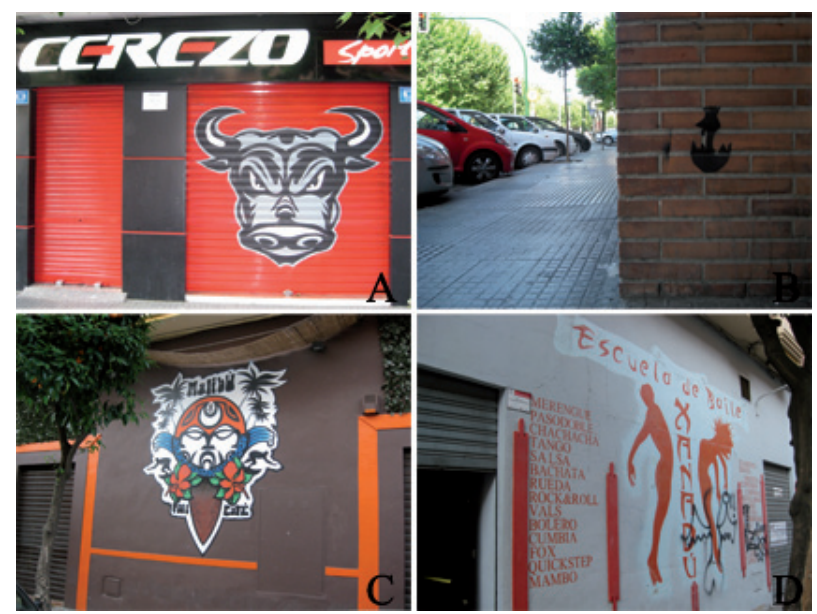

Figura 3. Piezas A, B, C y D de la figura 2.

(Fotografías de elaboración propia)

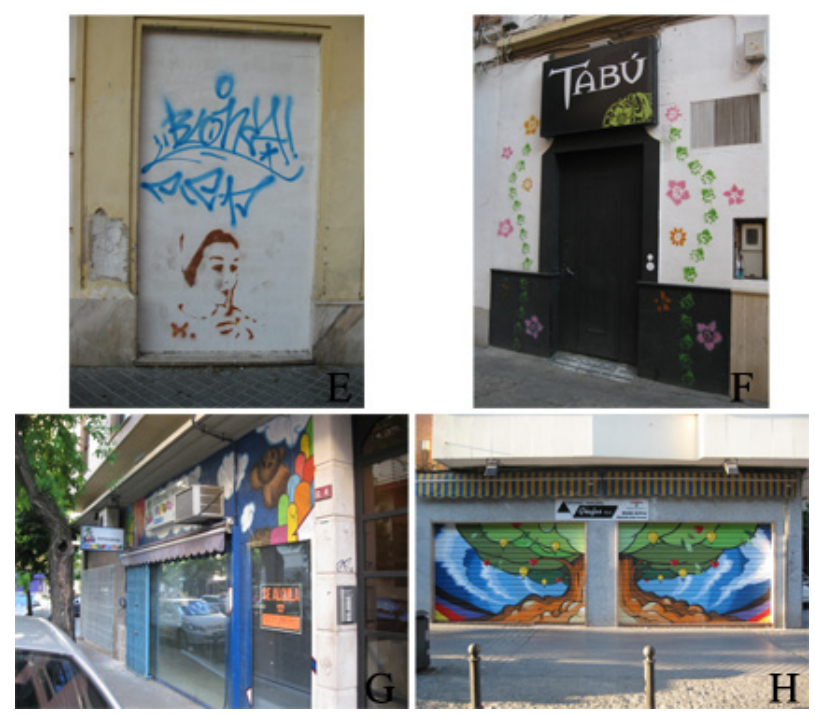

Figura 4. Piezas E, F, G y H de la figura 2

(Fotografias de elaboración propia) 

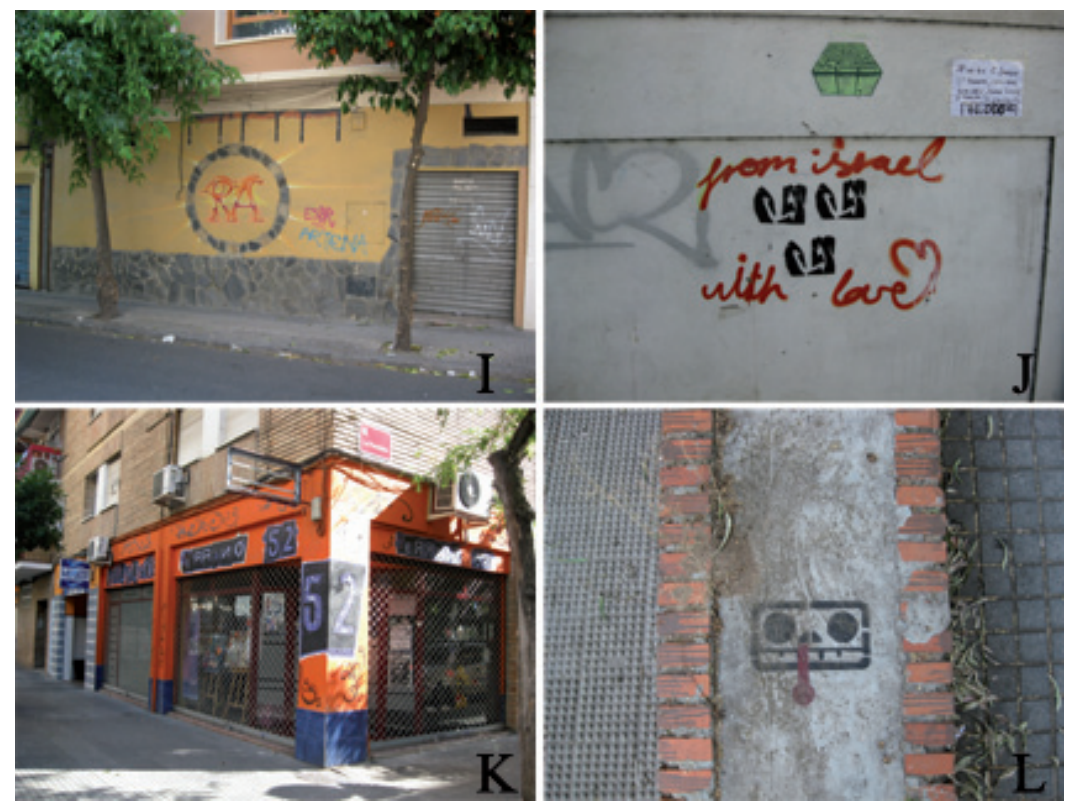

Figura 5. Piezas I, J, Ky L de la figura 2

(Fotografias de elaboración propia)

Gracias a la figura del flâneur (Cfr. Benjamin, 2005: 421-458), y sobre todo a la cartografía, hemos dado el salto desde el Street Art como constructo vago y abstracto hasta la realidad material y palpable que representan los grafitis, con los que podemos conectar...

\section{Estética y Filosofía del Arte (urbano)}

Las obras de arte son provocaciones. Nosotros no las explicamos, sino que polemizamos con ellas (Hauser, 1981: 9)

El siglo XX ha acabado con el arte tradicional. Tras las vanguardias -última manifestación del academicismo-, el Pop Art marcó una nueva dirección, un nuevo orden en el que todo es arte; o, idem, nada es arte (Cfr. Jiménez, 2002). Éste ha sido sustituido por la Filosofía del Arte, que se instala en nuestra relación con la obra, indagando en los porqués de nuestra conmoción emocional y la catarsis que de ella se deduce. Esto es, hablamos de Erótica y Hermenéutica (Cfr. Álvarez, 2007). 


\subsection{Erótica}

Tanto menos se goza de las obras de arte cuanto más se entiende de ellas (Adorno, 1983: 25)

La Erótica es la primera fase de la experiencia estética. Sobre ella debe recaer la reflexión, pues es aquello que nos vincula emocionalmente con la obra y crea una verdadera pasión por el arte. Sin embargo, esta faceta se ha menospreciado en las enseñanzas humanísticas a favor de una explicación histórica en la que prima el contenido y el contexto.

Se ha desarrollado toda una manera de hablar, una jerga en toda regla de discriminación de lo inmediato, de lo visual. [...] La crítica de la subjetividad en nombre de intersubjetividad, objetividad y demás había declarado la guerra al sujeto que percibe y conoce, que también padece y obra. [...] Conceptodependencia, mono de concepto o necesidad de muletas conceptuales son otras tantas maneras de nombrar una déformation profesionelle muy extendida (Schlögel, 2007: 265:269).

En los últimos años se han venido sustituyendo las deterministas teorías del reflejo, de ascensión marxista, por otras más centradas en la percepción subjetiva del receptor. En otras palabras, se llama ahora la atención sobre aquello que nuestros ojos no han sabido amar en su cotidiano vistazo: el arte necesita de recogimiento, un tiempo que nos regalamos a nosotros mismos para conversar con la obra y entablar la llamada transformación en construcción (Cfr. Gadamer, 1999: 154-166). Esta tesitura parece haber quedado relegada a los espacios museísticos, artísticos por extensión, que se revisten de una cierta "religión del arte" (Cfr. Alonso, 1999: 21). Ahora bien, la imperante obsolescencia del presente -véase el apartado 1-nos ha robado el placer de vivir la ciudad: bajo ningún concepto hemos de resignarnos ante su pérdida.

En este sentido, el graffiti es un puente tendido hacia dicho placer, que suscita potentes y encontrados sentimientos: por un lado, los amantes del Street Art perciben en sus valores plásticos una gran capacidad evocadora, quizá condicionada por lo ilegal de su presencia y su futuro incierto; por otro, los detractores de este fenómeno se comunican de igual modo con las obras, aunque generen sentimientos negativos. Sea como fuere, la Erótica es conditio sine qua non para el posterior proceso hermenéutico: no podemos negárnosla.

\subsection{Hermenéutica}

Si el arte ha muerto: ¿qué es el arte? (Román, 2007)

Dentro del binomio que hemos establecido, la Hermenéutica supone la culminación de la fase Erótica y, por ende, de la experiencia estética en sí misma. Entonces se 
produce realmente un crecimiento interior: consiste en utilizar el goce de los sentidos para proyectar la personalidad y descubrir las razones profundas de aquella emoción; desnudarnos de complejos para comprender nuestra esencia más íntima.

Tan importante es lo que vemos como lo que no vemos, que se encuentra presente por exclusión. Acaso la reflexión, en este caso, no se centre en la relación con la obra per se, sino en nuestra propia actitud. Las teorías actuales apuntan hacia una reinvención del concepto de arte en el papel activo del espectador. Según esta estética de la recepción, el arte existe en tanto que alguien lo contempla como tal e inicia un proceso de construcción, un diálogo continuo con la obra. Pero, ¿qué ocurre si la obra pasa desapercibida ante nuestros ojos? En un museo estamos (pre)dispuestos a buscar esa comunión con el objeto artístico que, en suma, no es otra cosa que una comunión con nosotros mismos: hemos decidido que queremos dedicarle un tiempo determinado de nuestra apretada agenda. Sin embargo, si lo encontramos acechando -literalmente-a la vuelta de la esquina, lo obviamos con el mayor de los desprecios. Aprender los mecanismos del arte tiene, por supuesto, sus factores positivos; pero educar nuestra percepción es también limitar nuestra experiencia a unos parámetros predeterminados. Definitio est negatio, máxime en el campo que nos atañe.

\subsection{Metaposición analítica}

An act of thought is an act of art [Un acto mental es un acto artistico] (Partum)

Podríamos añadir una tercera fase, independiente de las anteriores, a modo de síntesis hegeliana. En esta ocasión se centra el foco de atención en el propio proceso Erótico-Hermenéutico, ampliando así el espectro de nuestro trabajo: analizar la experiencia estética de una (hipotética) tercera persona alzándose un nivel por encima de ella, siendo conscientes de los mecanismos que subyacen a aquella observación de primer grado, discreta e ingenua en su individualidad. La observación de segundo orden correspondería a una metaposición analítica (Moyinedo, 2010) donde convergen todos los puntos de vista y desde la cual es posible emitir valoraciones de carácter universal.

La genealogía de la obra de arte se desdobla si consideramos una segunda posición de observación. [...] pierde su estabilidad ontológica, es decir que, escindiéndose de su manifestación material, se muestra ahora como resultado de un proceso cuya historicidad compromete no sólo las determinaciones de su origen sino también las de su destino (Moyinedo, 2010).

De esta manera, el espectador -o su defecto- se ve despojado de la neutralidad que garantizaba su anonimato; en resumen, interviene más o menos directamente en la creación, con un mayor o menor grado de autoría -ya innegable-, deviniendo responsable de su entorno. Dicha postura ofrece un enfoque global, que permite enjuiciar nuestro compromiso con la ciudad que vivimos, el paisaje urbano que conformamos a diario a través de nuestras actividades ya sean positivas o negativas. Y el veredicto puede derivar, consecuentemente, del Street Art: como arte urbano, representa sólo uno más de los elementos que nos pasan desapercibidos. Hemos de trascender 
las fronteras del arte y alcanzar las mentalidades -fin último de todo proyecto- para extraer conclusiones.

\section{Conclusiones: problemas y posibilidades del Street Art}

A lot of people never use their initiative because no-one told them to [Mucha gente no emplea nunca su propia iniciativa porque nadie le dijo que lo hiciera] (Banksy, 2001: 23)

A tenor de lo expuesto, ¿cuáles son los horizontes de expectativas para tales manifestaciones artísticas? Las nuevas corrientes destinadas a la musealización incurren en una flagrante contradicción: por un lado, el suculento mercado del arte puede suponer la fama y una nueva consideración del fenómeno -si bien se firma un pacto con el diablo, pues tan pronto como cesen sus repercusiones será desechado y olvidado-; por otra parte, el Street Art pretende ser un arte puro, al margen de cualquier exigencia tendenciosa ( $C f r$. Ruiz, 2009). Existe una alternativa a la simplista solución de encerrar las obras en un recinto museístico: mantener su esencia más profunda, aquella que le da nombre, dejándolas vivir en libertad (condicional). En este sentido, la propuesta de futuro pasa por la puesta en valor del Patrimonio -porque, sin duda, estamos hablando de Patrimonio- in situ, es decir, respetando sus características inherentes; aunque para ello tengamos que ser tolerantes y abrir la mente: podemos adoptar un modelo "ideal" -benchmarking-, o bien, dejar volar nuestra imaginación para crear un nuevo paradigma. En cualquier caso, necesitamos un cuerpo teórico -que, desde la modestia, hemos pretendido plasmar en este trabajo- sobre el cual sustentar la reflexión y del que se carecía hasta el momento.

En cuanto a la primera opción, si tomamos como ejemplo Londres -salvando las evidentes distancias- destacamos Street Art London Tours: una iniciativa privada que, por un módico precio, muestra el panorama de Arte Urbano londinense en una serie de rutas guiadas; por las condiciones especiales del objeto protagonista, se renuevan para cada cita: no existen dos iguales. Estos recursos se imbrican en una cultura callejera con mayor tradición, dentro de una estructura de la que se carece en Córdoba.

Algo más ambicioso y complejo sería aceptar el mobiliario urbano a modo de soporte artístico y concederlo como tal en el marco de un concurso de ideas. En ocasiones se critica a Córdoba por su aparente carácter rancio sin hacer referencia, precisamente, a su abolengo, sino a su omnipresente visión de color sepia: esta iniciativa, propia de un curador de las calles, podría actualizar dichas concepciones con una explosión de colores, solucionando de paso un "problema" público y aportando un nuevo atractivo a la ciudad. Año tras año, las arcas municipales destinan una importante cantidad de dinero a la limpieza de los grafitis presentes en sus infraestructuras. La creación de un programa iconográfico, de un discurso a través del cual ofrecer una imagen determinada -la temática podría renovarse- ha de entenderse como un ahorro para la comunidad y, al mismo tiempo, como un escaparate para el exterior; máxime, cuando en España es una práctica tan joven que despierta la curiosidad y tiene gran repercusión. 
Sea como fuere, las nuevas tecnologías habrán de jugar un papel principal en el orden que se establezca: debemos disponer y hacer disponible a aquel que lo requiera toda la información sobre la materia, dentro de un mapa temático de Street Art en Córdoba; y aquí cobraría importancia el estudio que se viene apuntando durante todo el artículo. Éste tendría que ser actualizado a menudo, pero contaría con una serie de elementos permanentes -aquellos dictaminados por el Ayuntamiento tras el concurso de ideas-.

Entonces, ¿es el Street Art una entelequia? Como hemos visto, existen algunas manifestaciones, mas Córdoba aún lo mantiene en un plano de inferioridad. A pesar de la contradictio in terminis, quizá haya que tender un puente a estos artistas hacia la legalidad y el reconocimiento mediante esta suerte de iniciativas, que pondrían en valor una dimensión de la ciudad apenas estudiada y que no puede continuar ocultándose. En definitiva, se trata de adaptar nuestros modelos al dinamismo y la pluralidad; de ampliar la oferta cultural de Córdoba hacia sectores y franjas de edad que hoy están cambiando el mundo; de hacer de la ciudad un monumento integral, por fin...

\section{Referencias bibliográficas}

AA.VV. (2005). Granada Graffiti. 2005-1989. Armilla: El Lunes

Adorno, T. (1983). Teoría estética. Barcelona: Orbis

Alonso, L. (1999). Museología y Museografía. Barcelona: Ediciones del Serbal

Álvaréz, L. (2007). La aporía del arte: 'hipertrofia' del entendimiento y 'represión' de la sensibilidad. En Fedro. Revista de Estética y Teoría de las Artes, 5, pp. 50-75

Banksy (2001). Banging Your Head Against a Brick Wall. United Kingdom: Weapons of Mass Distraction

Benjamin, W. (2005). Libro de los pasajes. Madrid: Akal

Cambil Hernández, M. E. (2012). Los graffitis y el espacio urbano: el 'niño de las pinturas'. Quiroga, 2, pp. 10-29

Cook, N. (2001). De Madonna al canto gregoriano. Una muy breve introducción a la música. Madrid: Alianza

De Diego, J. (2000). Graffiti, la palabra y la imagen: un estudio de la expresión en las culturas urbanas en el fin del siglo XX. Barcelona: Los libros de la frontera

Gadamer, H-G. (1999). Verdad y Método. Fundamentos de una hermenéutica filosófica, Volumen I. Salamanca: Sígueme

Hauser, A. (1981). Teorías del arte. Barcelona: Guadarrama

Hessel, F. (1984). Ein Flaneur in Berlin. Berlin

Jiménez, J. (2002). Teoría del arte. Madrid: Tecnos-Alianza

Julius, A. (2002). Transgresiones. El arte como provocación. Barcelona: Destino

Klein, N. (2001). NO LOGO. Barcelona: Paidós

Lefebvre, H. (1974). Le droit à la ville suivi de Espace et politique. Paris: Anthropos

López Jiménez, Á. (1998). El arte de la calle. Reis: Revista española de investigaciones sociológicas, 84 , pp. 173-194

Román, R. (2007). Del arte con fronteras a las obras nómadas. Si el arte ha muerto: ¿qué es el arte? Fedro, Revista de Estética y Teoría de las Artes, 6, pp. 4-18 
Ruiz, M. (2009). Disquisiciones graffiteras. Fedro. Revista de Estética y Teoría de las Artes, 8, pp. 39-50

Schlögel, K. (2007). En el espacio leemos el tiempo. Sobre Historia de la civilización y Geopolítica. Madrid: Siruela

Thiebaut, C. (1999). La mal llamada postmodernidad (o las contradanzas de lo moderno). En BOZAL, V. (ed.). Historia de las ideas estéticas y de las teorías artísticas contemporáneas, Volumen II (377-393). Madrid: Visor

\section{Referencias electrónicas}

Abarca Sanchís, F. J. (2010). El postgraffiti, su escenario y sus raíces: graffiti, punk, skate y contrapublicidad, (Tesis de doctorado, Universidad Complutense de Madrid). Recuperado de http://eprints.ucm.es/11419/1/T32410.pdf

Arjona, A.R. (2012, 14 de octubre). Callejero pirata: 'Por fin te he encontrado'. Diario Córdoba. Recuperado de http://www.diariocordoba.com/noticias/cordobalocal/callejero-pirata-por-fin-te-he-encontrado-_752624.html

Figueroa Saavedra, F. (1999). El 'graffiti movement' en Vallecas: historia, estética y sociología de una subcultura urbana, (1980-1996). (Tesis de doctorado, Universidad Complutense de Madrid). Recuperado de http://biblioteca.ucm.es/ tesis/19972000/H/0/H0041601.pdf

Lima Barbosa, L. R. (2011, 8 de noviembre). Conferencia inaugural de la celebración de los 80 años de Bellas Artes. Universidad de Caldas. Recuperado de http:// www.ucaldas.edu.co/index.php?option $=$ com_content\&view $=$ article \& catid $=419$ $\% 3$ Auniversidad-al-dia\&id=6419\%3A-una-sociedad-sin-arte-es-una-sociedadsin-vida-luis-roberto-lima-barbosa\&Itemid=1039

London Transport Museum (2012, 18 de mayo): Mind the map. Inspiring art, design and cartography. Recuperado de http://www.ltmuseum.co.uk/whats-on/exhibitions/past-exhibitions/395-exhibition-mind-the-map

Moyinedo, S. (2010): La obra de la crítica. Formulaciones metodológicas para una metacrítica. Figuraciones. Teoría y crítica de artes, 7. Recuperado de http://www. revistafiguraciones.com.ar/numeroactual/articulo.php?ida=154\&idn=7\&arch=1

Partum, E. (2001, 16 de abril): Ewa Partum. Retrospektive 1965-2000. Badischer Kunstverein. Recuperado de http://www.badischer-kunstverein.de/index.php?Dir ection $=$ Programm $\&$ list $=$ Ausstellungen $\&$ Jahr $=2001 \&$ Detail $=260$

Pérez, Y (2012, 26 de julio). Algo más que graffitis. Diario Córdoba. Recuperado de http://www.diariocordoba.com/noticias/contraportada/algo-mas-que-graffitis_732818.html

\section{Referencias musicales}

Black Star (1998): Respiration. Mos Def \& Talib Kweli are Black Star. Rawkus Records

Promoe (2004): These walls don't lie. The Long Distance Runner. Burning Heart Records 